\title{
Louis J. "Skip" Elsas II, MD, FACMG
}

Louis J. "Skip" Elsas II was a proud native of Atlanta, who was born into a family that greatly valued education. After a high school education at the Phillips Andover Academy, he graduated from Harvard College with a BS degree in biochemistry, which possibly heralded his life's work in biochemical genetics. After receiving his medical degree, with honors, from the University of Virginia, he trained in internal medicine at Yale, followed by a fellowship in metabolism, also at Yale. He was aware that genetics was the future of medicine and therefore became the first fellow along with Leon Rosenberg in Yale's new program, medical genetics. After his fellowship, and 2 years as a faculty member at Yale, he returned to Atlanta. At Emory,

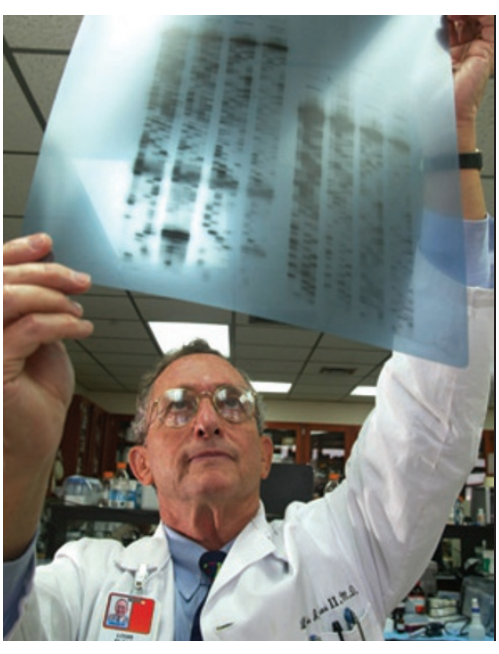

Louis J. "Skip" Elsas II, 10 February 1937-16 September 2012. he began building the program in medical genetics, which has become a genetics powerhouse. During his long, productive research career, he published more than 190 refereed articles that provided new information about many biochemical disorders in humans. Our understanding of maple syrup urine disease was greatly enhanced by his studies on the interaction of branched-chain a-ketoacid dehydrogenase with thiamine and thiamine pyrophosphate. Throughout his entire career, he published original research in an area of his life-long interest, galactosemia. His work in this area explored the mechanism of early ovarian failure, and in recent years he examined other mechanisms to treat galactosemia-such as developing inhibitors of galactokinase-which might prevent some of these complications. His interest in a point-of-care diagnostic technology for galactosemia led to his studies using total body galactose oxidation to $\mathrm{CO}_{2}$ (using 13C galactose) in expired air.

By the late 1970s, it had become clear that there was a need to increase knowledge of and to promote research in the area of inborn errors of metabolism in humans, and to enhance the interactions between clinicians and investigators in this area. In 1978, the Society for Inherited Metabolic Disorders (SIMD) was formed, with Skip as its first president. SIMD, nearly 35 years later, remains a vibrant and important professional organization, with Skip's involvement throughout.

His participation in the organization of professional groups did not stop there. In 1991, the growing need to develop a professional organization for the translation of medical genetics into clinical medicine led to the organization of the American College of Medical Genetics. Skip was a founding fellow and a life-long contributor to the work of this group. Today, the American College of Medical Genetics and Genomics is the leading organization for human medical geneticists in the world. Skip's role in genetic education has been extensive. In addition to his developing new and innovative courses for medical students at Emory over many years, he mentored a long series of trainees. He directly supervised nine $\mathrm{PhD}$ students and 33 fellows in genetics. He later collaborated with some of his former fellows in research projects in important areas such as the nutritional treatment of children with inborn errors of metabolism. His former fellows now hold important positions in medical genetics throughout the United States, in addition to Japan and Italy.

After building a remarkable program in medical genetics at Emory, and at an age when many are considering life on a sailboat, Skip embarked on a second career. In 2002, a generous multimillion dollar gift from the Dr. John T. MacDonald Foundation, of Coral Gables, FL, to the University of Miami, Miller School of Medicine, permitted the University to recruit Skip to Miami to establish a new program in medical genetics. He approached this task with gusto. He brought together the considerable talent already present at the Miller School of Medicine and recruited new bright, creative geneticists and fellows in genetics. His work led to the development of the new Dr. John T. Macdonald Department of Human Genetics and helped lay the foundation for the Hussman Institute for Human Genomics. During the past decade, it has been great for me to join Skip and his very special wife Nancy on many evenings in the street cafes of Coconut Grove, our home village within Miami. He continued to work full time, 7 years after his first diagnosis of metastatic prostate cancer. He was busy on his iPad even days before his death, communicating not only with friends, but also with his colleagues about scientific issues. My e-mails always got a quick response.

Skip was an innovative thinker and an outstanding physician. He received numerous awards, presented many named lectureships, chaired many groups, and was a true leader in medical genetics. He was a devoted husband, father, and grandfather. $\mathrm{He}$ was a beloved physician. At his memorial services at The Temple Atlanta, a magnificent structure on Peachtree Street in downtown Atlanta, hoards of friends, patients, and colleagues gathered to remember the remarkable life and contributions of Skip Elsas. He will be missed, but his many contributions are forever.

\section{R. Rodney Howell, MD}

Miami, Florida, USA.

doi:10.1038/gim.2012.148 